\title{
OS PRECEDENTES VINCULANTES \\ E O PROBLEMA DA CONTINGENCIA ONTOLÓGICA DO DIREITO
}

\author{
BINDING PRECEDENTS AND ONTOLOGICAL CONTINGENCY IN LAW
}

\section{LOS PRECEDENTES VINCULANTES Y EL PROBLEMA DE LA CONTINGENCIA ONTOLÓGICA $D E L D E R E C H O$}

\author{
Gerson Neves Pinto ${ }^{1}$
}

Igor Raatz ${ }^{2}$

\section{William Galle Dietrich ${ }^{3}$}

Licença CC BY:

Artigo distribuído sob os termos Creative

Commons, permite

uso e distribuição

irrestrita em qualquer

meio desde que 0

autor credite a fonte

original.

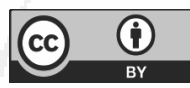

Resumo: O presente artigo visa revisitar o problema da contingência ontológica do Direito nas lições aristotélicas, com o fito de esclarecer como o Estagirita pensou a diferença entre praxis e poiêsis. Com isso, pretende-se sustentar que as teses precedentalistas no Brasil - sobretudo aquelas que enraizam seus objetivos teóricos na busca por mecanismos que forneçam previsibilidade e certeza ao Direito - ignoram que o problema de indeterminação do Direito é um problema ontológico, que não pode ser resolvido com nenhum "aparato epistemológico" e, por isso, passam a sustentar a cisão entre interpretação e aplicação. Em sede de conclusão, pretende-se, assim, demonstrar que o próprio marco inicial (ou o fundamento) de tais teorias é equivocado, motivo pelo qual todo o desenvolvimento teórico restante fica comprometido.

Palavras-chave: Aristóteles; Precedentes; Indeterminação do Direito; Hermenêutica.

1 Pós-doutor e Doutor pela École Pratique Des Hautes Etudes - Sorbonne (Paris). Mestre em Filosofia pela Universidade Federal do Rio Grande do Sul. Professor do Programa de Pós-Graduação em Direito da Universidade do Vale do Rio dos Sinos - UNISINOS (São Leopoldo/RS). E-mail: gersonp@unisinos.br.

2 Pós-doutor, Doutor e Mestre em Direito pela Universidade do Vale do Rio dos Sinos - UNISINOS (São Leopoldo/ RS). Especialista em processo civil pela Academia Brasileira de Direito Processual Civil - ABDPC. Membro do DASEIN - Núcleo de Estudos Hermenêuticos. Membro da ABDPro - Associação Brasileira de Direito Processual. Professor do curso de graduação em Direito da Universidade FEEVALE (Novo Hamburgo/RS). Advogado. E-mail: igor@raatzanchieta.com.br.

3 Mestrando em Direito Público pela Universidade do Vale do Rio dos Sinos - UNISINOS (São Leopoldo/RS), como bolsista CAPES/PROEX. Graduado em Direito pela Universidade FEEVALE (Novo Hamburgo/RS). Membro do DASEIN - Núcleo de Estudos Hermenêuticos. Membro da ABDPro - Associação Brasileira de Direito Processual. Advogado. E-mail: galledietrich@gmail.com. 
Abstract: This essay seeks to revisit legal questions raised by contingency and ontological incompleteness based on the Aristotelian lessons regarding the differences between praxis and poiêsis. It then seeks to affirm that the precedentalist conceptions in the Brazilian legal thought - especially those whose theoretical goals are supposedly the search for predictability and legal certainty - ignore the fact that legal indeterminacy is an ontological issue and therefore cannot be solved by way of an epistemological apparatus that supports a separation between interpretation and application. In conclusion, therefore, our goal is to demonstrate that the most fundamental premises of said theories is mistaken from the very beginning, which obviously compromises the whole of their theoretical development.

Keywords: Aristotle; precedents; legal indeterminacy; hermeneutics.

Resumen: El presente artículo visa revisitar el problema de la contingencia ontológica del Derecho en las lecciones aristotélicas, con el objetivo de esclarecer como el Estagirita pensó la diferencia entre praxis y poiêsis. Con esto, se pretende sustentar que las tesis precedentalistas en Brasil sobre todo aquellas que arraigan sus objetivos teóricos en la busca por mecanismos que fornecía previsibilidad y certeza al Derecho - ignoran que el problema de indeterminación del Derecho es un problema ontológico, que no puede ser resuelto con ningún "aparato epistemológico" y, por eso, pasan a sustentar la escisión entre interpretación y aplicación. En conclusión, se pretende, así, demostrar que el propio marco inicial (o el fundamento) de tales teorías es equivocado, motivo por el cual todo el desarrollo teórico restante queda comprometido.

Palabras-clave: Aristóteles; Precedentes; Indeterminación del Derecho; Hermenéutica.

\section{INTRODUÇÃO}

Uma das grandes questões jurídicas, que atravessa os séculos e nunca sai de pauta, é a questão da indeterminação do Direito. Não é de hoje que se escuta no meio jurídico, sobretudo nas palavras de indignados advogados, que é absolutamente inadmissível que os mesmos problemas jurídicos tenham soluções distintas. Não é por outro motivo, aliás, que correntes doutrinárias que defendem a tese de precedentes obrigatórios sempre fazem questão de lembrar a conhecida frase, que fica acima dos magistrados na Corte di Cassazione italiana: "La Legge è uguale per tutti".

A lei, é verdade, deveria ser igual para todos. Mas é sabido que ela não é. É comum no cotidiano forense a aplicação do Direito de modo irregular, ou até mesmo de forma diametralmente oposta em casos similares. É interessante notar, ainda, que isso sequer é algo inerente aos juízos de primeira instância, em que se sabe que a infraestrutura com a qual o magistrado opera é muito inferior 
àquilo que idealmente deveria dispor para tratar os processos com a devida atenção. Uma pesquisa jurisprudencial é capaz de mostrar que, mesmo nas altos Tribunais do país, isso também ocorre (e muito). Avançando, e deixando o "complexo de vira-lata" de lado, percebe-se que esse é um problema que permeia o âmbito jurídico de outros países também. Uma pesquisa rápida com a expressão da Corte di Cassazione revela isso e, guardadas as críticas políticas por detrás desse jargão, parece que a Itália não disporia de um filme de comédia, que tem o título de La legge è uguale per tutti... forse, se o seu Direito fosse de uma determinabilidade aritmética.

É claro que o Direito italiano não é de uma determinabilidade aritmética, assim como não é o brasileiro. Ocorre é que o problema não é italiano, ou brasileiro, mas antes, é um problema em nível mundial. O Direito não é plenamente determinado sequer nos países da common law, nunca foi e nunca será. Em outras palavras, essa indeterminação é contingencial e inerente à própria ontologia do Direito, razão pela qual não pode ser solucionada a priori. Jamais.

Com efeito, procurando esclarecer como isso já foi descoberto por Aristóteles, o presente artigo pretende revisitar as lições do Estagirita, para mostrar que muitas das soluções que foram buscadas ao longo dos séculos para sanar a indeterminação do Direito - como a pretensão de completude dos Códigos - não passaram de "idealismos jurídicos", na medida em que simplesmente desconsideraram a própria ontologia do Direito (e da linguagem).

Em um segundo momento, pretende-se mostrar como as teorias precedentalistas contemporâneas parecem sonegar, em um primeiro momento, essa importante constatação aristotélica para, em um segundo momento, incorrer em outro equívoco, que é acreditar na possibilidade de uma cisão entre interpretação e aplicação. Com isso, tem-se o intento de demonstrar que tais teorias estão viciadas em suas bases, na medida em que todo o seu desenvolvimento teórico parte de premissas filosóficas equivocadas.

1. Da atualidade jurídico-hermenêutica de Aristóteles: ou de como não se deve confundir o ofício do artesão com o do jurista 
Aristóteles e Platão foram, sem nenhuma dúvida, os maiores filósofos da história e essa afirmação sequer exige maiores justificações. Não é por outro motivo, aliás, que Alfred North Whitehead afirma que a filosofia ocidental consiste em uma série de notas de rodapé a Platão $0^{4}$. Ousar-se-ia complementar a afirmação de Whitehead com o adendo de que a filosofia ocidental é uma série de notas de rodapé a Platão e Aristóteles, precursores da civilização ocidental. Apesar de tudo isso, por motivos que não cabem ser abordados aqui, raramente se percebem acadêmicos preocupados em estudar seriamente suas obras, em que pese suas indispensáveis contribuições e sua incrível atualidade ${ }^{5}$.

Tendo em vista que um dos grandes problemas do Direito contemporâneo tem relação com o compreender, vale dizer, com a aplicação da fonte normativa ao caso concreto no qual ela incide, que a questão relativa ao (mau) uso de precedentes (forçadamente importados para o Direito brasileiro) pode ser problematizada e enfrentada com base nas lições propostas por Gadamer, as quais possuem bases explícitas em Aristóteles. Gadamer, na obra Verdade e Método, afirma que aquilo que está em jogo na compreensão da tradição "passa a ser um caso especial da aplicação de algo geral a uma situação concreta e particular"6. Disso se segue que a compreensão da tradição - assim como das leis - é um problema essencialmente ligado à interpretação de um (comando) universal para um caso particular, algo muito aprofundado na ética aristotélica. Gadamer tece tais considerações em um capítulo denominado "a atualidade hermenêutica de Aristóteles".

No referido capítulo, Gadamer ressalta que, contrapondo o intelectualismo socrático-platônico, Aristóteles segregou a ética como uma matéria praticamente autônoma frente à metafísica. Para Aristóteles, seria um equívoco equiparar a virtude ao saber, de forma que no âmbito da virtude, vale dizer, da filosofia prática, não haveria uma exatidão de nível matemático ${ }^{7-8}$. A consequência lógica

4 WHITEHEAD, Alfred North. Process and Reality: an essay in cosmology. N.Y.: The free press, 1978, p. 39.

5 Evidentemente que com raras exceções. Observe-se, por exemplo, texto de Eduardo José da Fonseca Costa, que demonstra como parte da gramática usada no Direito Processual é devida ao Estagirita: "O Título II do Livro I do CPC/39 já falava em "atos e termos judiciais". Na verdade, o uso conjugado das duas palavras é da tradição luso-brasileira (hoje ignorado pela neófila processualística hodierna brasileira). Deve-se fundamentalmente à influência de Aristóteles sobre o estudo do movimento do processo". COSTA, Eduardo José da Fonseca. Art. 188. In: STRECK, Lenio Luiz; NUNES, Dierle; Cunha, Leonardo (Orgs.). Comentários ao Código de Processo Civil. 2. ed. São Paulo: Saraiva, 2016. p. 299.

6 GADAMER, Hans-Georg. Verdade e Método. 15. ed. Petrópolis, RJ: Vozes, 2015, p. 411.

7 GADAMER, Hans-Georg. Verdade e Método. p. 411 e ss.

8 Cf. Höffe, "Aristotle develops his ethics as a matter of course practically without metaphysical premises. The relation 
Novos Estudos Jurídicos

disso é que não deveriam ser equiparadas as questões da ordem do conhecimento com as questões de ordem das ações ${ }^{9}$. Sabendo que, no nível da filosofia prática, trabalha-se apenas com uma verdade aproximada ${ }^{10}$, Aristóteles delimita o saber ético (phronêsis) e o saber teórico (epistêmê). Tal delimitação deve levar em conta que, "para os gregos, a ciência, representada pelo paradigma da matemática, é um saber do inalterável, que repousa sobre a demonstração e que, por conseguinte, qualquer um pode aprender"11. Isso fica muito claro na passagem em que Aristóteles afirma que "não seria menos insensato aceitar um raciocínio provável da parte de um matemático do que exigir provas científicas de um retórico"12.

Em Verdade e Método, Gadamer retoma esses ensinamentos do Estagirita justamente com o intento de reforçar seu argumento de que as denominadas "ciências do espírito" (Geisteswissenschaften) trabalham com um nível de verdade que opera para além do método. Tudo que envolve a estética, a história ou a linguagem (estando aqui o Direito) não se esgota em um método e em pretensões "matematizantes" - ensinamentos cujo embrião já estava em Aristóteles. Esse é o ponto central da hermenêutica filosófica gadameriana, que vai ao encontro da ética aristotélica.

No Direito, a questão do método já foi bastante abordada. As pretensões de conferir ao Direito um grau matemático já foram refutadas por inúmeros autores, dentre os quais se pode citar "apenas" Herbert Hart, que, como dito, constatou os problemas de indeterminação da linguagem ${ }^{13}$. Algumas vezes, as pretensões "matematizantes" - que, no limite, desconhecem a natureza da phronêsis - acabaram manifestando-se de forma um pouco mais velada, não deixando exatamente claro o intento de que se produza um rigor matemático no Direito, como é o caso do fenômeno que Ovídio Baptista da Silva cunhou com o nome de ordinariedade ${ }^{14}$; por outras vezes, tais pretensões de verniz aritmético adentram de

appears to be rather the inverse, since the question 'Why metaphysics?' is a practical, even existential, question. Ethics and metaphysics are largely independent of each other as philosophical disciplines, but the justification of a life dedicated to mere cognition, and ultimately to natural philosophy and metaphysics, belongs within the scope of ethics". HÖFFE, Otfried. Aristotle. Albany: State University of New York Press, 2003, p. 131, ARISTOTELES. Étique a Nicomaque. Traduit par Jules Tricot, Vrin: Paris, 1990, $1095 a 5$.

10 ARISTOTELES. Étique a Nicomaque. 1094b15.

11 GADAMER, Hans-Georg. Verdade e Método. p. 414.

12 ARISTOTELES. Étique a Nicomaque. $1094 \mathrm{~b} 25$.

13 HART, Herbert L. A. O Conceito de Direito. 3. ed. Tradução de A. Ribeiro Mendes. Lisboa: Fundação Calouste Gulbekian, 1994, passim.

14 Para estudo mais aprofundando ver RAATZ, Igor; LOPES, Ziel Ferreira; DIETRICH, William Galle. O que é isto: a 
forma explícita, como o caso de Jeremy Bentham, que, segundo sua corrente de comentadores majoritárias, acreditava que seu Pannomion poderia abarcar todas as situações fáticas futuras (em outros termos, seria um Código completo) ${ }^{15} \mathrm{ou}$, ainda, o mito da onipotência do legislador na Escola da Exegese francesa ${ }^{16}$.

Essa discussão parece, assim, exaurida no Direito. Parece tautológico dizer que não existe um nível de exatidão matemático no Direito, pois não há um nível de exatidão na linguagem e os códigos (sejam eles legislativos, sejam eles um conjunto de julgados porventura denominados de precedentes) não conseguem prever todas as situações da vida ${ }^{17}$. Por sinal, esses dois problemas, a saber, a indeterminação da linguagem e a questão da incompletude da legislação (e dos precedentes), são correlatos. Por vezes, evidentemente, a legislação simplesmente não apresenta qualquer regulamentação diante de um caso; contudo, ainda em casos regulamentados pelo Direito (o que algumas concepções chamariam de easy cases) verifica-se que a própria indeterminação da linguagem não é capaz de deixar claro, aprioristicamente, qual é, de fato, a solução, de modo que a resposta vai sempre depender do caso concreto (do particular).

Não há como predeterminar, por meio de alguma "ferramenta" ou um "método", a exatidão do fenômeno. No ponto, advém a magistral advertência de

ordinariedade? Perspectivas de superação no processo civil contemporâneo. Revista de Processo. vol. 272, ano 42, pp. 127-161. São Paulo: RT, outubro 2017.

15 FERRARO, Francesco. Adjucation and Expectations: Bentham on the Role of the Judges. Utilitas, vol. 25, n. 2, jun. 2013. Cambridgeshire: Cambridge University Press, 2013, pp. 140-160.

16 Ver BONNECASE, Julian. La escuela de la exegesis en derecho civil. México: Jose Cajica, 1944, p. 166 e ss. Norberto Bobbio demonstra, inclusive, que a pretensão de completude do Código Napoleônico sequer foi pensado originalmente como um ideal por seu principal redator, razão pela qual o art. 4. do referido código ( $O$ juiz que se recusar a julgar sob o pretexto do silêncio, da obscuridade ou da insuficiência da lei, poderá ser processado como culpável de justiça denegada) possuía originalmente uma função totalmente diversa daquela que lhe foi posteriormente atribuída pela Escola da Exegese: "na verdade, o art. $4^{\circ}$ não desempenha a função de válvula de segurança que garanta o poder de criação do direito por parte do juiz, como era a intenção de seus redatores e, em particular, de Portalis". Bobbio identifica cinco pontos que foram fundamentais para o advento da Escola da Exegese - e da nova atribuição de sentido ao art. $4 .^{\circ}$ do Código Napoleônico - dos quais vale destacar o ponto que trata das "pressões exercidas pelo regime napoleônico sobre os estabelecimentos reorganizados de ensino superior do direito [...], a fim de que fosse ensinado somente o direito positivo e se deixasse de lado as teorias gerais do direito e as concepções jusnaturalistas". BOBBIO, Norberto. $\mathbf{O}$ positivismo jurídico: lições de filosofia do direito. São Paulo: Ícone, 1995, p. 78 e ss. Com efeito, percebe-se que a concepção de completude do Código Napoleônico possuía notório caráter político, no sentido de realocação de poder. O poder criativo do Direito centralizava-se no legislativo por meio de uma ficção jurídica (código completo). Isso não difere muito dos precedentalistas que, conforme abordagem em tópico seguinte, trabalham com uma ficção jurídica (precedentes obrigatórios que garantem absoluta "unidade" ao Direito) para, no fundo, deslocar/limitar o poder interpretativo acerca do Direito apenas nas denominadas Cortes de Vértice.

17 Esses dois problemas, a saber, a indeterminação da linguagem e a questão da incompletude da legislação (e dos precedentes) é correlato. Por vezes, evidentemente, a legislação simplesmente não apresenta qualquer regulamentação diante de um caso; contudo, ainda em casos regulamentados pelo Direito (o que algumas concepções chamariam de easy cases), verifica-se que a própria indeterminação da linguagem não é capaz de deixar claro, aprioristicamente, qual é, de fato, a solução, de modo que a resposta vai sempre depender do caso concreto per se. 
Gadamer pautada em Aristóteles (ainda falando da ética): não esperar da instrução que se lhe oferece mais do que esta pode e deve dar ${ }^{18}$. Ao extremo, Gadamer está dizendo que o homem não dispõe de si mesmo como o artesão que dispõe do material com o qual trabalha. Quer-se, com isso, afirmar que o problema da indeterminação do Direito é um problema que não se resolve, se assim se quiser, "epistemologicamente". Não será um Código completo, súmulas, enunciados ou precedentes que resolverão esse problema, pois a própria natureza do Direito o condena a essa indeterminação. O Direito só é (mas não apenas) no particular ${ }^{19}$. O (caso) particular atropela sempre as pretensões aritméticas-apriorísticas do jurídico, razão pela qual se poderia dizer que o problema do Direito é, sobretudo, um problema que se encontra em um nível de sua própria natureza; no nível "do que é" o Direito (no nível ontológico) ${ }^{20}$.

Por isso o trabalho de um jurista difere - e muito - de um artesão, que está operando com a technê: "[o artesão] possui o projeto da coisa e as regras de sua execução, e a esta se aplica, pode ver-se obrigado também a se adaptar a circunstâncias e dados concretos, isto é, renunciar a executar seu plano exatamente como estava concebido originalmente. Mas essa renúncia não significa, de modo algum, que com isso se complete o seu saber daquilo que ele quer. Ele simplesmente faz reduções durante a execução. Isso é uma real aplicação de seu saber, vinculada a uma imperfeição dolorosa"21. Da mesma afirmou o Estagirita:

Há uma diferença entre produzir e agir [...] de sorte que a capacidade raciocinada de agir difere da capacidade raciocinada de produzir. Daí, também, o não

18 GADAMER, Hans-Georg. Verdade e Método. p. 413.

19 Com isso não se está sustentando uma posição particularista do Direito, como se não houvesse nada antes do surgimento do caso concreto. Tal postura, de que o Direito depende de situações meramente contingenciais não havendo nada que lhe anteceda é algo que se aproxima de um realismo jurídico. Nesse sentido, "Cada vez mais, os juristas ficam à mercê de decisões tribunalícias, como a dar razão ou a repristinar as velhas teses do realismo jurídico, pelas quais o Direito se realiza na decisão, forma acabada de um positivismo que, buscando superar o formalismo-exegético, abriu, historicamente, o caminho para discricionariedades e deciosinismos. É a tese de que 'o Direito é o que o judiciário disser que é'”. STRECK, Lenio Luiz. Verdade e Consenso: constituição, hermenêutica e teorias discursivas. 6. ed. rev. mod. e ampl. São Paulo: Saraiva, 2017, p. 297.

20 Alguém filiado às teses precedentalistas poderia argumentar que, para se levar em conta o caso particular é que existe, justamente, o distinguishing. Ocorre que, ao afirmar isso, tem como pressuposto necessária a ideia de que existem casos que são faticamente idênticos, o que é um severo equívoco. Um caso é sempre um caso que exsurge com um grau de particularidade, vale dizer, um caso nunca é exatamente igual ao outro. Para que se possa dizer que as razões de um precedente se aplicam em um caso $X$ é preciso que se analisem as condições particulares do caso $\mathrm{X}$ e, mais do que isso, é preciso que o caso $\mathrm{X}$ efetivamente exista. Em outros termos, os transcendentalistas estão operando com a racionalidade das ciências naturais dentro das ciências do espírito. Panoramicamente falando, na medicina, quando se encontra a cura para determinada patologia, é possível que se chegue a uma vacina, por exemplo. Depois da vacina, aquele case está resolvido antes mesmo de ocorrer, pois, a rigor, todos os casos daquela doença se manifestarão igualmente nos seres humanos. O Direito não funciona assim, pois não existem "vacinas" que resolvam o caso antes mesmo de ele aparecer, conforme pretendem os adeptos da tese ora contestada. 
se incluírem uma na outra, porque nem agir é produzir, nem produzir é agir. [...] Diferindo, pois, o produzir e o agir, a arte deve ser uma questão de produzir e não de agir; e em certo sentido, o acaso e a arte versam sobre as mesmas coisas ${ }^{22}$.

Esta diferença entre o jurista e o artesão radica na distinção feita por Aristóteles entre a praxis e a poiêsis ${ }^{23}$. No âmbito da ação humana, no âmbito da contingência, Aristóteles estabelece no Livro VI da Ética Nicomaqueia, cap. IV24, uma distinção fundamental entre a ação e a produção, a praxis e poiêsis. O objetivo essencial de Aristóteles neste capítulo é de distinguir a phrônesis da tékhnê e a razão principal que ele invoca é precisamente a de que a phrônesis refere-se à praxis, ao passo que a tekhnê diz respeito à poiêsis. No cap. 5 do livro sexto da Ética Nicomaqueia ${ }^{25}$, a phronèsis (Prudência) é cuidadosamente distinguida da sophia (Sabedoria). Se em Platão as duas noções eram utilizadas como sinônimo, Aristóteles atribui uma nova significação à noção de phronèsis. Sabedoria e Prudência são em Platão as virtudes do conhecimento teórico, orientadas em direção à contemplação do mundo transcendente das ideias. Em Aristóteles, é o termo sabedoria que mantém esta significação: ela é o conhecimento do universal, daquilo que se apresenta como necessário e logo, universal. Mas a Prudência, ao contrário, diz respeito ao mundo da contingência, isto é, diz respeito às coisas que podem ser diferentemente do que elas são, cujo princípio não é necessário e que compõe o que Aristóteles chama de mundo da contingência ${ }^{26}$, no qual se pode incluir o fato de que se encontram realidades que tanto podem não ser quanto podem $\operatorname{ser}^{27}$.

Quando se trata de conhecimento com relação ao mundo da contingência, é uma parte específica da razão que se encarrega, dirá Aristóteles: é a razão prática, orientada pela virtude superior que é a prudência, que deve deliberar ${ }^{28}$.

22 ARISTÓTELES. Étique a Nicomaque. 1140a1-1140a15.

23 Como muito bem lembrou Hannah Arendt, (ARENDT, Hannah. A condição humana. Rio de Janeiro: Forense Universitária, 2007, p. 15-30) Aristóteles estabeleceu a noção de práxis como sendo a ação imanente que tem seu fim nela mesma, em sua autorrealização. A poiêsis é, ao contrário, a produção de uma obra externa ao agente. Ora, afirma Hannah Arendt, a filosofia moderna, desde o seu início, substituiu o modelo da práxis pela poiêsis. 0 primado desta última sobre a primeira teve consequências consideráveis sobre a concepção que se faz do tipo de teoria adequada para normatizar a atividade humana: o cientificismo de Hobbes, por exemplo, quando ele afirma que no Leviatã, cap. V "Razão nada mais é do que cálculo". HOBBES, Thomas. Leviatã. Coleção Os Pensadores, São Paulo: Abril Cultural, 1979, p. 20.

24 ARISTOTELES. Étique a Nicomaque. 1140a1-1140a20.

25 ARISTOTELES. Étique a Nicomaque. 1140a25-1140b30.

26 Sobre a gênese do conceito de mundo, sobretudo em Platão e Aristóteles, ver o clássico estudo de Rémi Brague em La Sagesse du Monde: Histoire de l'expérience humaine de l'univers. Ed. Fayard, Paris, 1999.

27 ARISTOTELES. Étique a Nicomaque. 1140a1.

28 No tratado Movimento dos Animais, Aristóteles fornece mais informações sobre o processo de deliberação. A 
Deliberação, então, é um tipo de investigação efetuada pela razão prática com a finalidade de determinar o que deve ser realizado nas circunstâncias particulares nas quais ocorre a ação. Trata-se aqui de um saber cujo fim não é o saber por ele-mesmo, mas que é constituído em vista da ação.

Assim, como visto anteriormente, Aristóteles distingue duas atitudes fundamentais do homem: a atitude contemplativa ou o saber que se refere ao necessário e à atitude prática, o fazer que se refere ao contingente. E é sobre o contingente que o homem pode deliberar, que ele pode escolher ${ }^{29}$. Ao descrever logicamente o tipo de raciocínio prático envolvido na deliberação, Aristóteles não está pensando somente na ética, mas também faz um paralelo com a técnica, especialmente a medicina e a navegação, que funcionavam no mundo grego como paradigmas para explicar a ação humana.

Em toda a teoria da deliberação sobre a tomada de decisão em casos e em situações de incerteza, Aristóteles utilizava-se dessa comparação, entre a deliberação moral (a deliberação propriamente prática) e a deliberação técnica. Ao introduzir a noção de deliberação nas primeiras frases da Ética Nicomaquéia ${ }^{30}$, ele o faz justamente mediante essa comparação entre a ação prática e a técnica, ou a arte.

Mas, apesar dessa similaridade, desse parentesco, o Estagirita mostra que há uma diferença lógica entre a deliberação técnica e a deliberação da justiça política (na ação humana). No caso da deliberação judicial (do juiz) existe um aspecto ontológico intransponível da contingência do caso concreto e dos vários aspectos circunstanciais relevantes que podem ocorrer e que impedem que esta deliberação se limite apenas à análise universal e abstrata da lei. O juiz equânime delibera

ação representa a conclusão de uma deliberação. No caso do homem, a imagem do silogismo chamado "prático" pode ajudar a compreender como seria uma deliberação. Tome-se o exemplo da passagem 701a17-22 do tratado Movimento dos Animais: "tenho necessidade de me cobrir; ora um cobertor serve para cobrir; tenho necessidade de um cobertor. Isto do qual tenho necessidade, é necessário que eu o faça; tenho necessidade de um cobertor; é necessário pois fazer um cobertor". A conclusão deste silogismo representa a ação a ser realizada, o objeto desejado. ARISTÓTELES. Mouvement des Animaux. Texte établi et traduit par P. Louis, Paris: Les Belles Lettres, 1973.

29 No entanto, Aristóteles estabelece duas exceções à deliberação no domínio do contingente. Segundo o Estagirita, existem coisas que, mesmo contingentes, realizam-se na natureza sem nenhuma necessidade, mas sem que o seu surgimento seja o efeito de uma deliberação ou de uma escolha: são de dois tipos - 1) as coisas que são o efeito do "acaso" (o automaton) e, 2) de outra parte, aquelas que são o efeito da "fortuna" (o tyché), o acaso sendo a ausência da causalidade natural interna e a fortuna a ausência da causalidade técnica externa. ARISTÓTLES. Métaphysique. Traduit par Jules Tricot, Vrin: Paris, 1986, 1070a9-10.

ARISTOTELES. Étique a Nicomaque. $1112 \mathrm{~b} 1$. 
a partir das circunstâncias e consegue assim recolocar a lei em sua singularidade. Este juiz "não é outro senão o homem justo e prudente, aquele que toma as decisões em função e imerso na particularidade de cada ação" ${ }^{131}$. Segundo Zingano ${ }^{32}$, existe essa indeterminação no campo das ações que é antes ontológica do que epistêmica, ou seja, é uma indeterminação da própria ação como tal e não de um problema de maior ou menor conhecimento das variáveis envolvidas.

Desta forma, o que diferencia esta deliberação envolvida na técnica da deliberação judicial é que, nesta última, a indeterminação não é uma questão de conhecimento, mas, como diz Aristóteles, é uma indeterminação com relação à matéria das ações humanas, ou como já referido, é um problema que não se resolve "epistemologicamente". Em outras palavras, é porque a matéria em que se dá o agir humano é ontologicamente variável, e isto, inexoravelmente, que o agir ético será sempre contingente e jamais se poderá extingui-la, nem sequer diminuí-la com o incremento de nosso conhecimento. Aristóteles acredita que as ações sempre se dão no terreno ontologicamente indeterminado e esta indeterminação de base não depende do conhecimento, mas diz respeito ao tipo de matéria que envolve as ações: a contingência ontológica.

\section{A CONSEQUÊNCIA DA CONFUSÃO ENTRE PHRÔNESIS E TÉKHNÊ: UMA CISÃO ENTRE INTERPRETAÇÃO E APLICAÇÃO}

Aparentemente, não haveria nenhum desacordo entre a postura aqui defendida e a tese levantada por boa parte dos precedentalistas brasileiros, no sentido de uma inexorável indeterminação do Direito. Porém, chega-se à mesma constatação por caminhos diferentes, e isso tem repercussões importantes, as quais abarcam tanto o modo de compreender os precedentes judiciais quanto o otimismo neles depositado para conferir segurança jurídica e igualdade.

Frise-se que autores como Luiz Guilherme Marinoni, Daniel Mitidiero e Sérgio Cruz Arenhart reconhecem o caráter indeterminado da linguagem seguindo o filão teórico desenvolvido na Itália a partir de Giovanni Tarello, para

31 ZINGANO, Marco. Estudos de ética antiga. São Paulo: Discurso Editorial, 2007, p. 348.

ZINGANO, Marco. Estudos de ética antiga. p. 329. 
quem não haveria uma relação "biunívoca" entre enunciado e proposição ${ }^{33}$, de modo que a intepretação consistiria tanto no processo de individualização de uma proposição expressa num enunciado (interpretação atividade), quanto a própria proposição individualizada (interpretação produto) ${ }^{34}$. Nessa linha, a norma seria uma das possíveis proposições produto da interpretação ou, dito de outro modo, o significado de um segmento de linguagem ${ }^{35}$.

Sem querer polemizar com pontos específicos do pensamento de Tarello, Guastini - para quem "os juízes de última instância são livres para atribuir aos textos normativos qualquer significado" ${ }^{36}$, o que se considera já ser um problema grave - e demais representantes do realismo jurídico genovês ${ }^{37}$, é importante deixar claro que referida corrente teórica passa longe da applicatio gadameriana, cindindo, portanto, intepretação e aplicação. Guastini, por exemplo, afirma que a interpretação teria como objeto textos normativos, enquanto que a aplicação teria por objeto normas, vale dizer, o conteúdo de sentido dos textos normati$\operatorname{vos}^{38}$. Tarello vai mais longe e afirma que "toda atividade de aplicação pressupõe uma atividade de interpretação, enquanto nem toda atividade de interpretação pressupõe uma atividade de aplicação" ${ }^{39}$. Não causa estranheza, portanto, que Marinoni, Mitidiero e Arenhart afirmem categoricamente que "a aplicação do direito não se confunde com a sua interpretação", e indo além, digam que nem toda interpretação tem por fim a aplicação do direito. Com isso, os autores citados constroem a tese de que o Direito sofreria de uma dupla indeterminação: por um lado, os textos seriam equívocos; por outro, as normas seriam vagas ${ }^{40}$.

33 TARELLO, Giovanni. Enunciati, enunciazioni e spie della loro funzione precettiva. Diritto, enunciati, usi: studi di teoria e metateoria del diritto. Bologna: Società editrice il Mulino, 1974, p. 176.

34 TARELLO, Giovanni. L’interpretazione della lege. Giuffrè: Milano, 1980, p. 34.

35 TARELLO, Giovanni. II problema dell'interpretazione: una formula ambigua. Rivista internazionale di filosofia del diritto, XLIII, fasc. 2, 1966, p. 353.

36 GUASTINI, Riccardo. Interpretare e argomentare. Milano: Dott. A. Giuffrè Editore, 2011, p. 412.

37 As menções a Giovanni Tarello e Riccardo Guastini são uma constante por parte dos doutrinadores mencionados, o que tem levado muitas pessoas a considerá-los uma espécie de leitura obrigatória para se falar em "teoria da interpretação". Não é por acaso que, em seu curso de processo civil (volume 1), no capítulo destinado à interpretação, Marinoni, Mitidiero e Arenhart fazem referência a eles em oito oportunidades. Já Mitidiero (no livro Cortes Superiores e Cortes Supremas) busca assentar os pressupostos teóricos do seu modelo de Cortes Supremas mais de vinte vezes.

38 GUASTINI, Riccardo. Estudios sobre la interpretación jurídica. Tradicción: Marina Gascón, Miguel Carbonell. México: Universidad Nacional Autónoma de México, 1999, p. 10.

39 TARELLO, Giovanni. Orientamenti analitico-linguistici e teoria dell'interpretazione giuridica. Diritto, enunciati, usi: studi di teoria e metateoria del diritto. p. 408.

40 MARINONI, Luiz Guilherme; MITIDIERO, Daniel; ARENHART, Sérgio Cruz. Novo curso de processo civil: teoria do processo civil. Volume 1. São Paulo: Revista dos Tribunais, 2015, p. 51. 
Essa cisão entre interpretar e aplicar é justamente um dos elementos chave da tese precedentalista, que faz com que sua teoria represente um descolamento do caso concreto. Isso fica bem claro quando trabalham com o seguinte exemplo:

Saber, por exemplo, se a inviolabilidade domiciliar ('a casa é o asilo inviolável do indivíduo', art. 5०., XI, da CF) protege igualmente o escritório profissional privativo de determinada pessoa é uma questão que depende da outorga de sentido a um termo equívoco: casa. Apenas depois de sabermos qual o significado constitucional apropriado do termo casa para efeitos de proteção da pessoa é que poderemos pensar em resolver o problema ligado à extensão da inviolabilidade domiciliar no direito brasileiro ${ }^{41}$.

O trecho mencionado reflete uma espécie de retorno à hermenêutica romântica, criticada por Gadamer justamente por, não obstante reconhecer a unidade interna da compreensão e da interpretação (intelligere e explicare), ter expulsado totalmente do contexto da hermenêutica o terceiro momento da sua problemática, ou seja, a aplicação. É que, na compreensão, segundo ele, "sempre ocorre algo como uma aplicação do texto a ser compreendido à situação atual do intérprete" 42 .

Nessa linha, Gadamer reconhece que, tanto para a hermenêutica jurídica quanto para a teológica é constitutiva a tensão que existe entre o texto proposto - da lei ou do anúncio - e o sentido que alcança sua aplicação ao instante concreto da interpretação (que nada mais é que o caso particular) no juízo ou na pregação ${ }^{43}$. Isso já era possível visualizar em Bultmann, teólogo e historiador cuja influência sobre a obra de Gadamer costuma ser esquecida ${ }^{44}$. Com efeito, a 41 MARINONI, Luiz Guilherme. MITIDIERO, Daniel. ARENHART, Sérgio Cruz. O novo processo civil. São Paulo: Revista dos Tribunais, 2015, p. 412.

42 GADAMER, Hans-Georg. Verdade e Método. p. 406-407.

43 GADAMER, Hans-Georg. Verdade e Método. p. 408.

44 Sobre o tema, há um relevante estudo de Jean Grondin intitulado "Gadamer and Bultmann". GRONDIN, Jean. Gadamer and Bultmann. In: POKORNY, J.; ROSKOVEC, J. (Dir.). Philosophical Hermeneutics and Biblical Exegesis. Tübingen: Mohr Siebeck, Wissenschaftliche Untersuchungen zum Neuen Testament, 2002. p. 121143. Ainda a respeito dessa questão, André de Melo Araújo afirma que "a teoria hermenêutica que sublinha a estrutura válida da pré-compreensão não é encontrada por Gadamer exclusivamente nos textos heideggerianos. Também Rudolf Bultmann (1884-1976), teólogo da historicidade de Marburg, muito embora certamente apoiado em Heidegger, assuma a validade da pré-estrutura. Percebemos que a influência da obra de Bultmann em Gadamer não é tão clara quanto no caso de Heidegger, ou pelo menos nosso autor não a evidencia de forma explícita em suas notas e referências. Ainda que alguns poucos comentadores trabalhem de forma muito rápida essa ligação, acreditamos que ela seja mais determinante do que o próprio Gadamer nos deixa supor. Dez anos antes da publicação de Verdade e Método, o teólogo de Marburg escreve um artigo em que se pode reconhecer o mesmo trajeto da hermenêutica posterior traçado por Gadamer. Em O Problema da Hermenêutica (1950), 
noção de pregação como proclamação de Bultmann residia justamente no fato de o pregador, ao proclamar a palavra de Deus, se encontrar frente à comunidade e, ao mesmo tempo, ser ele um ser humano ao qual a palavra é dirigida ${ }^{45}$, sendo tais palavras "ditas aqui e agora como interpelação dirigida a ouvintes específicos numa situação concreta", qualificando aquele instante do ouvinte, chamando-o à decisão ${ }^{46}$.

Quanto aos textos jurídicos, a interpretação deve concretizá-la em sua validez jurídica, por isso, "se quisermos compreender adequadamente o texto", vale dizer, "compreendê-lo de acordo com as pretensões que ele apresenta, devemos compreendê-lo a cada instante, ou seja, compreendê-lo em cada situação concreta de uma maneira nova e distinta"47. Por isso, "compreender, no sentido de conhecer e explicar, implica logo algo de semelhante a uma aplicação ou a uma relação do texto com o presente" 48 . É justamente nesse sentido que Bultmann dizia que "a compreensão de um texto nunca é definitiva, mas permanece aberta, porque em cada futuro o sentido da escritura se manifesta de nova maneira" 49 . Isso nada mais é do que, no Direito, reconhecer a primazia do caso concreto (ou do particular) sobre quaisquer pretensões a priori e matematizantes depositadas nos precedentes judiciais.

Aqui fica claro como a cisão entre interpretação e aplicação das teses precedentalistas decorre da sua incapacidade de perceber que o Direito carece ontologicamente do aspecto contingencial/particular. Primeiro, imaginam que o

Bultmann percorre os textos de Schleiermacher e DILTHEY, além de fazer referência ao Iluminismo alemão, a Herder e ao Historicismo, ao Conde de York e a Ranke, para só então poder encaminhar a hermenêutica em uma direção que pode ser facilmente reconhecida como influenciada pelo autor de Ser e Tempo, e por meio da qual - muito embora o artigo de Bultmann seja deixado de lado na reconstrução das influências presentes no pensamento gadameriano em nome da força dos escritos de Heidegger - vê-se como o teólogo configura o problema da hermenêutica de forma muito próxima àquela que Gadamer irá apresentar uma década depois. Por mais que Gadamer cite muito esparsamente os escritos do seu amigo de Marburg dos anos de 1920, sustentamos que a presença deste não pode ser menosprezada, até mesmo porque tal trabalho serviu no mínimo para fazer nosso autor lembrar da importância da hermenêutica, sobre o qual já escutara algo valioso muito tempo antes, mais precisamente nos seminários de Heidegger de 1923". ARAÚJO, André de Melo. A atualidade do acontecer: o projeto de mediação histórica na hermenêutica filosófica de Hans-Georg Gadamer. São Paulo: Humanitas, 2008, p. 57-58. Ainda sobre a influência de Bultmann sobre Gadamer, com uma abordagem menos incisiva, ver ZACCARIA, Giuseppe. Ermeneutica e giurisprudenza: i fondamenti filosofici nella teoria di Hans Georg Gadamer. Milano: Dott. A. Giuffrè Editore, 1984, p. 40-42.

BULTMANN, Rudolf. Crer e compreender: ensaios selecionados. Ed. rev. e ampl. Tradução de Walter Schlupp, Walter Altmann e Nélio Schneider. São Leopoldo: Sinodal, 2001, p. 372. 
Direito pode ser produzido sem o particular, vale dizer, que os problemas jurídicos podem ser todos resolvidos aprioristicamente. Ao imaginar um Direito sem casos particulares, passam a cindir discursos de interpretação e aplicação.

Fica claro quando Marinoni afirma, sustentando sua tese de precedentes obrigatórios, que "a máxima de que 'casos similares devem ser tratados da mesma forma' é insuportável àqueles que se acham no direito de ter as suas reivindicações tratadas de forma particular"50. Ora, não se trata de "se achar estar no direito de ter seu caso tratado como particular", pois isso não é uma coisa passível de convenção: a própria demanda da natureza do Direito exige que o particular seja levado em consideração. Veja que o próprio processualista faz uso da expressão "casos similares". Bom, se são casos similares não são casos iguais e, logicamente, têm algo de particular. Lembrem-se de Aristóteles: do universal para o particular. O jurista também afirma que "um sistema judicial caracterizado pelo respeito aos precedentes está longe de ser um sistema dotado de uma mera característica técnica". Mas sua proposta é contrária a esse enunciado, se se levar em conta a diferença entre technê e phronêsis na obra de Aristóteles, pois a ideia dos precedentes é que os casos já estejam resolvidos antes mesmo de aparecerem em sua particularidade, quase que da mesma forma como o artesão produz o seu trabalho.

Portanto, é preciso cuidado, pois a bandeira de igualdade sustentada por essa tese pode se tornar meio para que ocorra justamente o contrário. Lembremse aqui casos de "precedentes" como os da legítima defesa ${ }^{51}$, nos quais a observação de "enunciados sem coisas" que desconsideravam o particular serviu (e ainda serve), justamente, para criar situações desiguais: o mesmo precedente serviu tanto de fundamento a favor quanto contra o réu. Se a "ferramenta" for aplicada no atacado, sem a observância das especificidades do caso particular, como parecem querer os precedentalistas, tem-se uma grande chance de se criarem muito mais problemas do que os que se pretendem sanar.

Também é preciso dizer que essa observação do particular (no sentido

50 MARINONI, Luiz Guilherme. Respeito ao Direito, Corte de Precedentes e Responsabilidade Pessoal. Disponível em: <http://www.marinoni.adv.br/home/artigos/>. Acesso em: 21 nov. 17.

51 STRECK, Lenio Luiz. Enunciado self service, feito em workshop, virou fonte para preventiva. Consultor Jurídico, São Paulo, 2016. Disponível em: <https://www.conjur.com.br/2016-jan-14/senso-incomum-enunciado-self-servicefeito-workshop-virou-fonte-preventiva>. Acesso em: 22 nov. 2017. 
aristotélico) não implica uma relativização. É justamente isso que Gadamer procura em Verdade e Método: demonstrar que existem verdades nas ciências do espírito, independentes da subjetividade, para além do método e do conhecimento progressivo da legalidade (Gesetzmässigkeit) ${ }^{52}$. Não se está pregando uma irracionalidade ou qualquer coisa do gênero, mas, antes, fazendo-se um importante alerta: não serão os precedentes que vão sanar o problema natural do Direito, de indeterminação da linguagem. A teoria dos precedentes obrigatórios parece ter o ser fundamento ético ancorado na hipótese de que os precedentes devem ser obrigatórios face ao seu poder de uniformizar o Direito, algo que não passa de uma utopia. Seu fundamento principal é equivocado, algo que acaba comprometendo todo o seu restante. Não existiu um Código completo até hoje e não serão os precedentes que terão essa completude também, pois é da natureza do Direito ser indeterminado aprioristicamente (a sua contingência ontológica). Quando Aristóteles segregou a ética da metafísica; quando diferenciou a tékhnê da phrônesis, tinha justamente a natureza dessa questão como fundamento. Não se pode simplesmente sonegar aquilo que Aristóteles magistralmente percebeu e tampouco aparenta ser sábio ignorar os ensinamentos de um filósofo que, em muitas questões, permanece com mais de dois mil anos de absoluta razão.

Ademais, não há como pressupor uma cisão entre uma função cognitiva e interpretativa, mormente para o Direito, na medida em que, nas palavras do próprio Gadamer, "o conhecimento do sentido de um texto jurídico e sua aplicação a um caso jurídico concreto não são dois atos separados, mas um processo unitário"53. Isso reivindica a aplicação um caráter prático ${ }^{54}$. Gadamer sabe muito bem que o Direito é um bom exemplo para construção do seu projeto hermenêutico, principalmente porque, "quando o juiz adapta a lei transmitida às necessidades do presente, quer certamente resolver uma tarefa prática"55. 0 compreender hermenêutico deve, pois, em cada caso, contemplar, entre as condições da própria possibilidade e validade, a aplicação do significado do texto à situação de vida prática do intérprete ${ }^{56}$.

52 GADAMER, Hans-Georg. Verdade e Método. p. 38.

53 GADAMER, Hans-Georg. Verdade e Método. p. 409.

54 Desse caráter prático, "afirma-se o fato de que a compreensão - exatamente como a ação - é sempre um risco, e não permite a simples aplicação de um saber geral de regras para o entendimento de enunciados ou textos dados". GADAMER, Hans-Georg. A razão na época da ciência. Tradução de Ângela Dias. Rio de Janeiro: Tempo Brasileiro, 1983, p. 75.

55 GADAMER, Hans-Georg. Verdade e Método. p. 430.

56 ZACCARIA, Giuseppe. Ermeneutica e giurisprudenza: i fondamenti filosofici nella teoria di Hans Georg Gadamer. Milano: Dott. A. Giuffrè Editore, 1984, p. 73. 
Não existe, portanto, uma pura e objetiva compreensão de sentido, que, posteriormente, na aplicação ao questionamento atual, adquira especial significado $^{57}$, na medida em que Direito não é technê, mas sim phronêsis. O sentido da applicatio, que representa um elemento constitutivo de todo compreender, não é o de uma "aplicação" posterior e externa de algo que originalmente já seria para si ${ }^{58}$. A aplicação, não é, portanto, o emprego posterior de algo universal, compreendido primeiro em si mesmo e depois aplicado ao caso concreto. É, antes, a verdadeira compreensão do próprio universal que todo texto representa para nós ${ }^{59}$.

Desse modo, é impossível descolar o sentido de um texto normativo do caso concreto, de modo a, num segundo momento, tomá-lo como universal e simplesmente aplicá-lo no caso futuro já previamente resolvido pelo próprio precedente. Essas concepções refletem-se na própria tentativa de conceitualização dos precedentes, considerados, por boa parte da doutrina brasileira, como "razões generalizáveis que podem ser identificadas a partir de decisões judiciais"60.

\section{CONSIDERAÇÕES FINAIS}

Com o estudo desenvolvido no presente artigo, pôde-se perceber que um dos principais equívocos das teorias precedentalistas é, justamente, tentar resolver um problema jurídico desconhecendo a questão da ontologia jurídica. Sabe-se que a indeterminação do Direito é algo de sua própria natureza, sendo inviável sanar tal problema por meio de qualquer "aparato" epistemológico. Duas pessoas, cada qual com casos aparentemente idênticos e soluções distintas: isso é irracional? Aparentemente, sim; contudo isso não é um privilégio do Direito brasileiro, mas sim algo de sua natureza. Questões como essa aconteceram no passado, acontecem atualmente e vão acontecer no futuro. E não só no Direito brasileiro, pois isso é uma característica do próprio Direito. Uma tentativa - virtual

\footnotetext{
57 GRONDIN, Jean. Introdução à hermenêutica filosófica. Tradução e apresentação de Benno Dischinger. São Leopoldo: Ed. Unisinos, 1999, p. 193.

58 GADAMER, Hans-Georg. Verdade e método II: complementos e índice. Petrópolis, RJ: Vozes, 2002 1986, p. 131.

59 GADAMER, Hans-Georg. Verdade e Método. p. 447.

60 MARINONI, Luiz Guilherme; MITIDIERO, Daniel; ARENHART, Sérgio Cruz. Novo curso de processo civil: tutela dos direitos mediante procedimento comum. p. 610.
} 
e idealista - de sequestrar a contingência do Direito não resolverá esse problema que perdura a humanidade desde o surgimento da civilização ocidental.

Por tudo isso, conclui-se que os precedentalistas foram buscar na epistemologia uma solução ontologicamente incompatível com o Direito. Se se quiser fazer uma metáfora, afirmar que o Direito pode ser matematicamente determinado aprioristicamente por uma dada "ferramenta" é o mesmo que afirmar que, com o devido treinamento (epistemologia), pode-se ensinar um cão a respirar debaixo d'água e viver como um peixe (desafiando a própria natureza - ontologia - da "coisa" cão). Então, acreditar realmente no sentido de uma dimensão preocupada efetivamente com a verdade e não velada por outros interesses, que os "precedentes obrigatórios" vão sanar completamente o problema de indeterminação do Direito, é autoflagelar-se com um castigo similar àquele sofrido por Tântalo: sempre muito perto, mas sempre muito longe.

Com isso, em sede de conclusão, quer-se dizer que não se encontra nenhum fundamento racional para que a tese dos precedentes seja seguida do modo apresentado pelos autores que propõem a sua obrigatoriedade, em que pese venha sendo constantemente citada pelos ministros dos Tribunais Superiores. Seu fundamento teórico é equivocado, na medida em que buscam (i) construí- la a partir de uma leitura malfeita de Bentham ${ }^{61}$; e (ii) lutam contra a própria natureza do Direito, que é indeterminado (e não relativo), buscando argumentar essa luta em uma ética pela igualdade do Direito. Por isso, a única coisa que tal teoria efetivamente terá (e já tem) sucesso é naquilo que não está dito: na sua capacidade redistributiva de poder. Sob a desculpa de uma unidade do Direito, o "poder" produtivo ${ }^{62}$ - que é inerente ao Direito dos juízos de $1^{\mathrm{a}}$ e $2^{\mathrm{a}}$ instância será paulatinamente aniquilado, sendo desnecessário listar todas as razões pelas quais isso não é bom, na medida que todos os textos que criticaram a tese dos

61 Cf. Streck, Raatz e Morbach, "Bentham defendia uma reforma no direito inglês a partir da codificação. Sua campanha não consistia em defender, juntamente com o direito estatutário, uma estabilização do direito judiciário com a obrigatoriedade dos precedentes da common law: mais que isso, o próprio common law era alvo de fortes críticas do autor, cujo pensamento, inclusive, já apontava para os riscos de uma rigidez de precedentes vinculantes, uma vez que estes poderiam estar errados desde sua origem. Portanto, ao contrário do que usualmente vem sendo afirmado, Bentham não era um entusiasta da doutrina do stare decisis justamente por saber os riscos que representa uma teoria que legitima a autoridade judiciária a errar por último". STRECK, Lenio Luiz; RAATZ, Igor; MORBACH, Gilberto. Desmistificando o positivismo de Jeremy Bentham: sua codificação utilitarista e a rejeição ao stare decisis como autorização para errar por último. Revista Brasileira de Direito Processual. Belo Horizonte, ano 25, n. 99, jul./set. 2017.

62 STRECK, Lenio Luiz. Dicionário de Hermenêutica: quarenta temas fundamentais da Teoria do Direito à luz da Crítica Hermenêutica do Direito. Belo Horizonte: Casa do Direito, 2017, pp. 97-103. 
precedentes obrigatórios já fizeram isso com um rigor impecável.

Por fim, vale fazer uma última observação para mostrar que tal tese não possui sequer consistência lógica: as teses precedentalistas/transcendentalistas partem do pressuposto de que o Direito é indeterminado, uma vez que a linguagem sofre de ambiguidade, porosidade, etc. A solução apresentada são os precedentes obrigatórios. Ocorre que os precedentes, pelo fato de também serem, inevitavelmente, forjados em linguagem, serão sempre passíveis de interpretação. Não podem, pois, os precedentes também serem porosos, ambíguos, etc.? E, no ponto, mais uma vez recorre-se ao Estagirita, transformando esse texto em um daqueles que é apenas mais uma nota de rodapé à filosofia dos parteiros da civilização ocidental: ou a linguagem é indeterminada ou não é. Tertium non Datur.

\section{REFERÊNCIAS DAS FONTES CITADAS:}

ARAÚJO, André de Melo. A atualidade do acontecer: o projeto de mediação histórica na hermenêutica filosófica de Hans-Georg Gadamer. São Paulo: Humanitas, 2008.

ARENDT, Hannah, A condição humana. Rio de Janeiro: Forense Universitária, 2007.

ARISTOTELES. Étique a Nicomaque. Traduit par Jules Tricot, Vrin: Paris, 1990.

ARISTOTELES. Métaphysique. Traduit par Jules Tricot, Vrin: Paris, 1986.

ARISTOTELES. Mouvement des Animaux. Texte établi et traduit par P. Louis, Paris: Les Belles Lettres, 1973.

BOBBIO, Norberto. $\mathbf{O}$ positivismo jurídico: lições de filosofia do direito. São Paulo: Ícone, 1995.

BONNECASE, Julian. La escuela de la exegesis en derecho civil. México: Jose Cajica, 1944.

BRAGUE, Rémi. La Sagesse du Monde: Histoire de l'expérience humaine de l'univers. Ed. Fayard: Paris, 1999.

BULTMANN, Rudolf. Crer e compreender: ensaios selecionados. Ed. rev. e ampl. Tradução de Walter Schlupp, Walter Altmann e Nélio Schneider. São Leopoldo: Sinodal, 2001.

COSTA, Eduardo José da Fonseca. Art. 188. In: STRECK, Lenio Luiz; NUNES, Dierle; Cunha, Leonardo (orgs.). Comentários ao Código de Processo Civil. 2. ed. São Paulo: Saraiva, 2016.

FERRARO, Francesco. Adjucation and Expectations: Bentham on the Role of the Judges. Utilitas, vol. 25, n. 2, jun. 2013. Cambridgeshire: Cambridge University Press, 2013. 
Novos Estudos Jurídicos

GADAMER, Hans-Georg. A razão na época da ciência. Tradução de Ângela Dias. Rio de Janeiro: Tempo Brasileiro, 1983.

GADAMER, Hans-Georg. Verdade e método II: complementos e índice. Petrópolis, RJ: Vozes, 20021986.

GADAMER, Hans-Georg. Verdade e Método. 15. ed. Petrópolis, RJ: Vozes, 2015.

GRONDIN, Jean. Introdução à hermenêutica filosófica. Tradução e apresentação de Benno Dischinger. São Leopoldo: Ed. Unisinos, 1999.

GUASTINI, Riccardo. Estudios sobre la interpretación jurídica. Tradicción: Marina Gascón, Miguel Carbonell. México: Universidad Nacional Autónoma de México, 1999.

GUASTINI, Riccardo. Interpretare e argomentare. Milano: Dott. A. Giuffrè Editore, 2011.

HART, Herbert L. A. O Conceito de Direito. 3. ed. Tradução de A. Ribeiro Mendes. Lisboa: Fundação Calouste Gulbekian, 1994.

HOBBES, Thomas. Leviatã. Coleção Os Pensadores, São Paulo: Abril Cultural, 1979.

HÖFFE, Otfried. Aristotle. Albany: State University of New York Press, 2003.

MARINONI, Luiz Guilherme. Respeito ao Direito, Corte de Precedentes e Responsabilidade Pessoal. Disponível em: <http://www.marinoni.adv.br/home/artigos/>. Acesso em 21 nov. 17.

MARINONI, Luiz Guilherme; MITIDIERO, Daniel; ARENHART, Sérgio Cruz. O novo processo civil. São Paulo: Revista dos Tribunais, 2015.

MARINONI, Luiz Guilherme; MITIDIERO, Daniel; ARENHART, Sérgio Cruz. Novo curso de processo civil: teoria do processo civil. Volume 1. São Paulo: Revista dos Tribunais, 2015.

PALMER, Richard. Hermenêutica. Tradução Maria Luísa Ribeiro Ferreira. Lisboa: Edições 70, 1999.

POKORNY, J.; ROSKOVEC, J. (Dir.). Philosophical Hermeneutics and Biblical Exegesis. Tübingen: Mohr Siebeck, Wissenschaftliche Untersuchungen zum Neuen Testament, 2002.

RAATZ, Igor; LOPES, Ziel Ferreira; DIETRICH, William Galle. O que é isto: a ordinariedade? Perspectivas de superação no processo civil contemporâneo. Revista de Processo. vol. 272, ano 42, pp. 127-161. São Paulo: RT, outubro 2017.

STRECK, Lenio Luiz. Dicionário de Hermenêutica: quarenta temas fundamentais da Teoria do Direito à luz da Crítica Hermenêutica do Direito. Belo Horizonte: Casa do Direito, 2017.

STRECK, Lenio Luiz. Enunciado self service, feito em workshop, virou fonte para preventiva. Consultor Jurídico, São Paulo, 2016. Disponível em <https://www.conjur.com.br/2016-jan-14/ 
senso-incomum-enunciado-self-service-feito-workshop-virou-fonte-preventiva >. Acesso em 22 nov. 2017.

STRECK, Lenio Luiz. Verdade e Consenso: constituição, hermenêutica e teorias discursivas. 6. ed. rev. mod. e ampl. São Paulo: Saraiva, 2017.

STRECK, Lenio Luiz; RAATZ, Igor; MORBACH, Gilberto. Desmistificando o positivismo de Jeremy Bentham: sua codificação utilitarista e a rejeição ao stare decisis como autorização para errar por último. Revista Brasileira de Direito Processual. Belo Horizonte, ano 25, n. 99, jul./set. 2017.

TARELLO, Giovanni. Enunciati, enunciazioni e spie della loro funzione precettiva. Diritto, enunciati, usi: studi di teoria e metateoria del diritto. Bologna: Società editrice il Mulino, 1974.

TARELLO, Giovanni. L’interpretazione della lege. Giuffrè: Milano, 1980.

WHITEHEAD, Alfred North. Process and Reality: an essay in cosmology. N.Y.: The free press, 1978.

ZACCARIA, Giuseppe. Ermeneutica e giurisprudenza: i fondamenti filosofici nella teoria di Hans Georg Gadamer. Milano: Dott. A. Giuffrè Editore, 1984.

ZINGANO, Marco. Estudos de ética antiga. São Paulo: Discurso Editorial, 2007. 